\title{
REFLEXÕES SOBRE A FORMA URBANA LATINO-AMERICANA O APORTE DOS CONGRESSOS PAN-AMERICANOS DE ARQUITETOS E DA SOCIEDAD INTERAMERICANA DE PLANIFICACIÓN, 1920-1976
}

\author{
REFLECTIONS ON LATIN AMERICAN URBAN FORM \\ THE CONTRIBUTION OF PAN AMERICAN \\ CONGRESS OF ARCHITECTS AND INTER-AMERICAN \\ PLANNING SOCIETY, 1920-1976
}

v. 7, n. 10

jan/ago (2015)

ISSN 1982-0569
José Carlos Huapaya Espinoza Programa de Pós-Graduação em Arquitetura e Urbanismo Universidade Federal da Bahia e-mail: jhuapayae@gmail.com

\section{Resumo}

Qual o papel dos profissionais latino-americanos na construção e reflexão sobre a forma urbana das cidades latino-americanas? Como de seu esse processo de reflexão? De que forma o conjunto de experiências e estudos elaborados davam conta dos processos e formação da cidade na América Latina? A partir da análise da temática discutida nos Congressos Pan-Americanos de Arquitetos e nos Encontros da Sociedad Interamericana de Planificación tentamos mostrar que houve preocupação por parte dos profissionais latinoamericanos, de um lado, na busca de uma base teórica "adequada" à realidade latino-americana e, pelo outro, no interesse por entender a problemática urbana, além dos processos de formação e construção das cidades latino-americanas.

\section{Palavras-chave}

Forma urbana, América Latina, Congressos Pan-Americanos de Arquitetos, Sociedade Interamericana de Planejamento.

\begin{abstract}
What is the role of Latin American professionals in the construction and reflection on the urban form of the Latin American cities? How the set of experiences and studies elaborates explained the processes and form of the city in Latin America? From the analysis of the theme discussed in the Pan-American Congress of Architects and the Meetings of the Inter-American Society of Planning we try to demonstrate that Latin American professionals were concerned, on the one hand, in the search for a theoretical basis "adequate" to the Latin American reality and on the other, in the interest in understanding the urban problems and the processes of formation and construction of Latin American cities.
\end{abstract}

\section{Keywords}

Urban form, Latin America, Pan-American Congress of Architects, Inter-American Society of Planning.

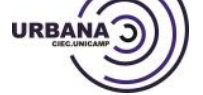

REVISTA ELETRONICA DO CENTRO INTERDISCIPLINAR DE ESTUDOS DA CIDADE - CIEC.UNICAMP 


\section{Introdução}

Qual o papel dos profissionais latino-americanos na construção e reflexão sobre a forma urbana das cidades latino-americanas? Como de seu esse processo de reflexão? De que forma o conjunto de experiências e estudos elaborados davam conta dos processos e formação da cidade na América Latina? Quais foram as formas de divulgação desses estudos? Responder a esse conjunto de questões é o objetivo do presente artigo. Para isso, tomamos como objeto de investigação dois dos encontros profissionais mais importantes da região: os Congressos Pan-Americanos de Arquitetos (CPA) concretizados a partir de 1920 e os Encontros da Sociedade Interamericana de Planejamento (SIAP) realizados a partir de 1956. Ambos os eventos constituíram-se em centros privilegiados de discussão de temas comuns aos países da América Latina a diferença daquilo que se desenvolvia em outros eventos internacionais como, por exemplo, Congressos Internacionais de Arquitetura.

Uma primeira aproximação aos CPA e a os encontros da SIAP mostra, de forma geral, a emergência e continuidade da temática aqui desenvolvida, a qual se prolongou e intensificou até o final da década de 1960, momento em que, se produz de forma clara uma ruptura que significou, em muitos casos, a incorporação de uma nova agenda. Por essa razão optamos por analisar somente os encontros realizados até meados da década de 1970.

Além disso, centramo-nos na produção editorial da SIAP a partir da análise dos artigos publicados na sua revista e dos livros editados por ela. Ambos os casos relevam-nos, antecipadamente, formas de divulgação que tinham como principal objetivo atingir um público alvo maior e diversificado.

\section{O debate sobre a cidade latino-americana nos Congresos Panamericanos de}

\section{Arquitectos, 1920-1975}

Os Congressos Pan-Americanos de Arquitetos (CPA) ${ }^{1}$ idealizados ainda em 1916 pela Comisión Directiva de la Sociedad de Arquitectos del Uruguay, mas, realizados

\footnotetext{
${ }^{1}$ Entre o período de estudo aqui proposto foram realizados os seguintes encontros: I CPA (Montevideo, 1920), II CPA (Santiago do Chile, 1923), III CPA (Buenos Aires, 1927), IV CPA (Rio de Janeiro, 1930), V CPA (Montevideo, 1940), VI CPA (Lima, 1947), VII CPA (Havana, 1950), VIII CPA (México, 1952), IX CPA (Caracas, 1955), X CPA (Buenos Aires, 1960), XI CPA (Washington, 1965), XII CPA (Bogotá, 1968), XIII CPA (San Juan, 1970), XIV CPA (São Paulo, 1972) e XV CPA (México, 1975). Uma primeira aproximação
} 
efetivamente quatro anos depois tiveram, desde sua gênese, preocupação por temas diversos os quais, no entanto, tinham como objetivos principais a "aproximação entre os profissionais da América" e as eventuais "vantagens que pudessem resultar da realização de uma obra em comum" (CPA, 1921, p.3)². Apesar de que alguns desses temas foram recorrentes e centrais desde os primeiros encontros, como por exemplo aqueles vinculados ao reconhecimento e à regulamentação da profissão no continente (GORELIK, 2005), eles tornaram-se cada vez mais diversificados possibilitando discussões sobre habitação, patrimônio, urbanismo, planejamento e ensino da Arquitetura.
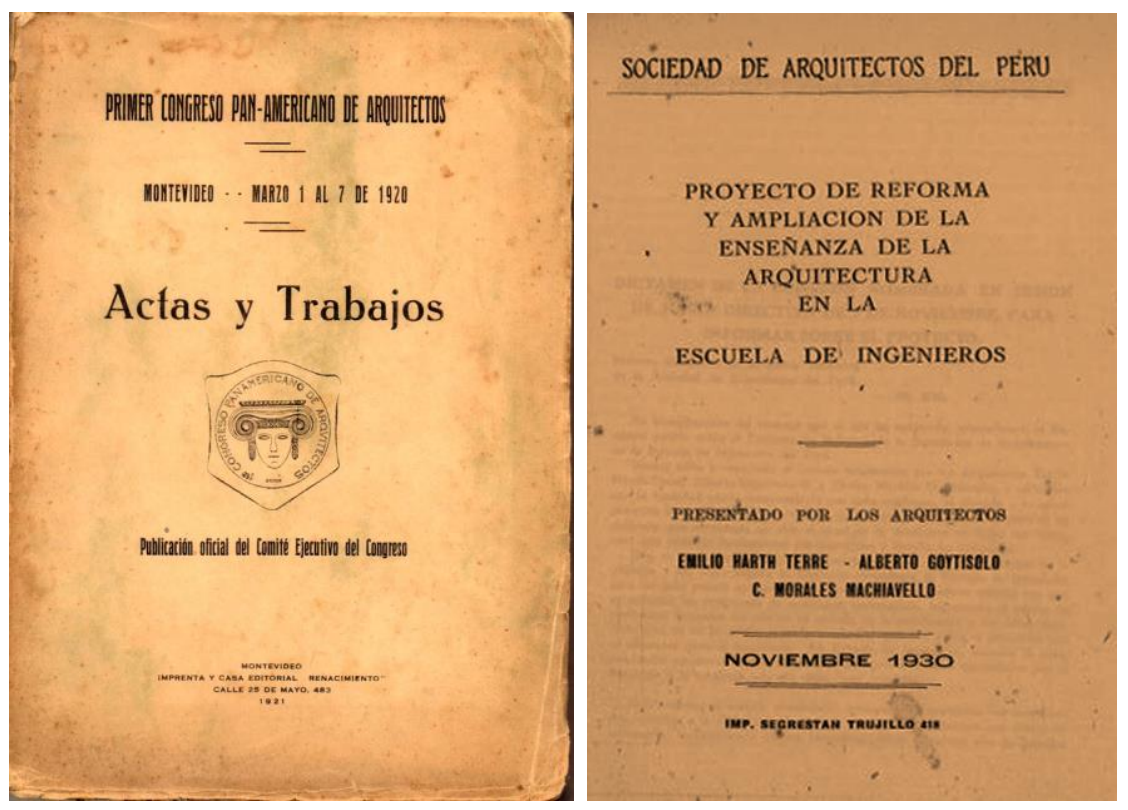

Figuras 1 e 2 - Atas do I Congreso Panamericano de Arquitectos e Livro Proyecto de Reforma y Ampliación de la Enseñanza de la Arquitectura en la Escuela de Ingenieros (1930), Lima-Peru, elaborado pela Sociedad de Arquitectos del Perú.

Uma análise da temática oficial dos congressos mostra que não houve de forma específica e implícita preocupação pelo debate sobre a "história do urbanismo latinoamericano" ou a "forma urbana latino-americana" embora muitas das cidades do

às discussões dos congressos evidencia um câmbio de foco a partir da década de 1970, por essa razão, neste artigo optamos por fazer nossa análise até congresso de 1968. Para um estudo mais aprofundado sobre os CPA ver: GUTIÉRREZ; TARTARINI; STAGNO (2007) e ATIQUE (2014).

2 Para Atique (2005) esses e os demais congressos pan-americanos não podem ser dissociados do debate sobre o "congraçamento das Américas" que tem seus primórdios na doutrina Monroe. 
continente passassem naquele momento por processos de crescimento acelerado iniciados, em especial, a partir da década de 1940. Ambos os temas, como veremos mais adiante, serão tratados de forma tangencial a partir de outras discussões como, por exemplo, a revisão da estrutura curricular do curso, a pertinência das unidades de vizinhança como alternativa à falta de moradia e os problemas sociais gerados, justamente, pelo aumento da população nos principais centros urbanos latinoamericanos.

Em parte, isto pode ser entendido se pensarmos que para esses congressos Arquitetura e Urbanismo eram considerados em um primeiro momento como uma disciplina só; posteriormente, o segundo seria entendido como uma especialização própria do arquiteto $(\mathrm{CPA}, 1950, \mathrm{p} .185-186)^{3}$. Nesse contexto, houve sim interesse pela construção conjunta da história da Arquitetura latino-americana. Para atingir esse alvo acreditava-se que os cursos específicos ministrados nas Escuelas de arquitetura deveriam levar em consideração as particularidades locais de cada país para dessa forma obter "por complementação" uma "grande obra de História da Arquitetura na América" (CPA, 1921, p.178).

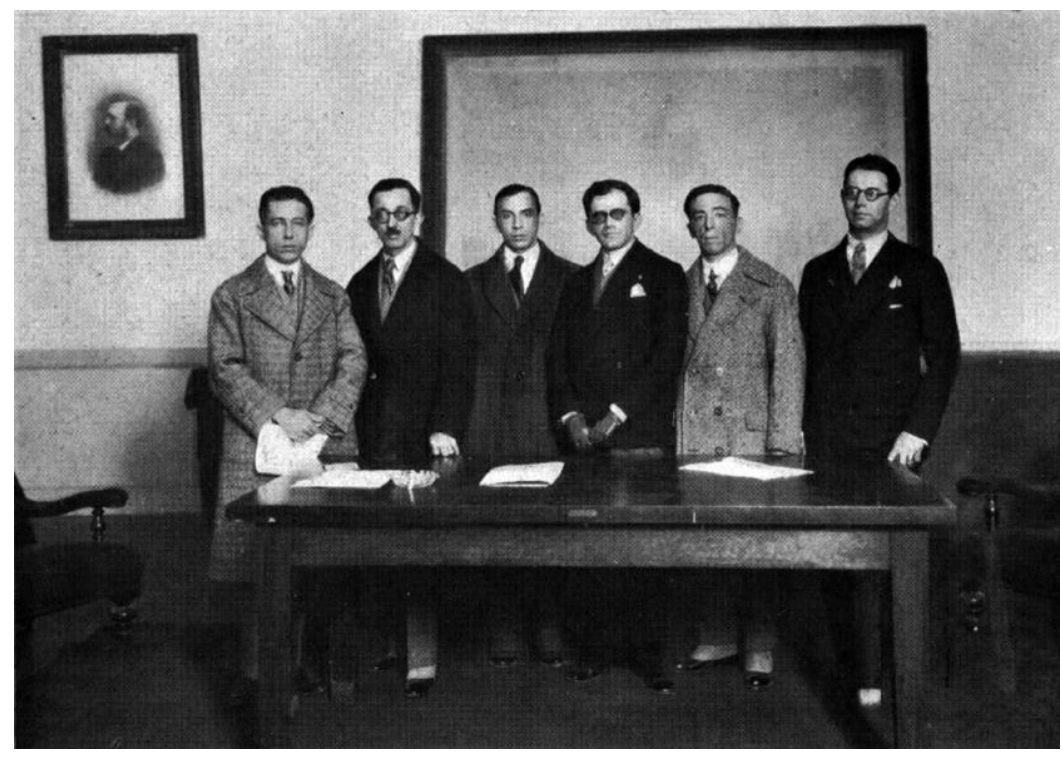

Figura 1 - Delegação brasileira no III CPA. Fonte: Revista de Arquitectura, a.XIII, n.79, jul. 1927.

\footnotetext{
${ }^{3}$ Essa conclusão foi aprovada a partir da comunicação "Ciencia y Arte en Urbanismo y Arquitetura" apresentada pelo arq. Henry S. Churchill. Outro aspecto colocado foi a função do arquiteto como "coordenador da realização urbanística".
}

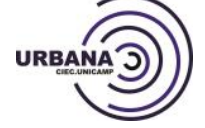

REVISTA ELETRONICA DO CENTRO INTERDISCIPLINAR DE ESTUDOS DA CIDADE - CIEC.UNICAMP 
As discussões sobre a proposta de padronização da estrutura curricular a qual permitiria o reconhecimento do título profissional em todos os países do continente incluía, também, a incorporação da disciplina de Urbanismo ${ }^{4}$. A partir do 30 CPA (1927) as funções dos arquitetos foram ampliadas à escala da cidade; a partir desse momento, os congressos começaram a defender as atribuições e a acreditação dos arquitetos como os professionais mais capacitados para dar forma à cidade. Para isso, a ideia do plano regulador ou plano de extensão, que nesse momento ganhava grande difusão ${ }^{5}$, tornou-se instrumento chave (CONCLUSIONES, 1927, p.314). No congresso seguinte (1930) essa visão meramente morfológica foi amadurecida ao considerar que para o desenvolvimento desses planos era necessário levar em consideração o "passado histórico, o ambiente e os costumes" das cidades com a finalidade de conservar suas caraterísticas inerentes (LAS CONCLUSIONES, 1930, p.544). No 50 CPA (1940) é possível identificar uma nova etapa na discussão e renovação da Arquitetura e do Urbanismo como resultado dos dez anos transcorridos desde o último congresso y da situação gerada pela Segunda Guerra Mundial.

De fato, o debate sobre questões urbanas que se desenvolveu nos países latinoamericanos acompanhou o ritmo e os processos de urbanização pelo quais passavam. Além disso, a conjuntura decorrente da deflagração da guerra permitiu revisões e redefinições de estratégias políticas e ideológicas (GOMES; HUAPAYA, 2009, p.29). A partir deste momento nota-se um interesse por entender, controlar, organizar e dar adequada forma à cidade. Isto é claro ao afirmar-se que "a extensão superficial ou intensificação em altura, depende de circunstâncias e fatores que devem apreciar-se em cada caso particular, em relação direta com o processo fundamental da composição urbanística" e que "como alternativa à caótica conformação daquilo que se entende por cidade atual, excessivamente torturada por edifícios em altura, em forma ilógica, deve estimular-se a redistribuição planejada" (CPA, 1940, p.115). Essas afirmações mostram uma visão e reflexão mais ampla dos problemas das cidades e sua relação direta com os habitantes as quais, por sua vez, foram resultado da incorporação, nas discussões

\footnotetext{
${ }^{4}$ As repercussões dessa discussão, no caso peruano, foram contundentes no Proyecto de Reforma $y$ Ampliación de la Enseñanza de la Arquitectura (1930) da então Escuela de Ingenieros del Perú elaborado pelos arquitetos Emilio Harth-Terré, Alberto Goytisolo e Carlos Morales Machiavello. Ao respeito ver: HUAPAYA, 2014a, p.73-77.

5 Para Tafuri, a expansão e aceitação do uso do plano devem entender-se como consequência da crise de 1929. Ver: LIERNUR, 2004, p.18.
} 
dos congressos, de "conceitos" trazidos da sociologia, da geografia humana e "demais disciplinas cientificas relacionadas com as agrupações humanas" (CPA, 1940, p.115). Esse enfoque foi retomado após a reorganização dos encontros no VI CPA (1947). Nessa ocasião, dois temas desenvolvidos chamam a atenção. O primeiro é a discussão sobre a função social da Arquitetura e a responsabilidade do arquiteto diante do progresso da técnica e do avanço social da mesma (CPA, 1953, p.188). O papel desempenhado pelo arquiteto diante da situação do pós-guerra era entendido como sua ação para enfrentar o problema da moradia através de aspectos econômicos, sociais e técnicos.

O outro tema é justamente a proposta formal dessa moradia. A partir desse congresso passou a ser promovida e defendida a construção de unidades de vizinhança (UV) em todo o continente. Elas eram consideradas como o elemento básico e estruturador da cidade e, portanto, definiriam sua forma tanto nas áreas de expansão quanto nas já consolidadas. O conceito de UV formulado por Clarence Arthur Perry no final da década de 1920 era baseado na ideia de uma área residencial autossuficiente ${ }^{6}$ e havia sido bastante divulgado no continente e, inclusive, havia servido de base para novas e paradigmáticas experiências de habitação social, dentre elas, podemos destacar no México, o Centro Urbano Presidente Alemán (1948) e o Centro Urbano Presidente Juárez (1951), do arquiteto Mario Pani e; no Peru, a Unidad Vecinal No3 (1948) elaborada pela Comisión Nacional de la Vivienda praticamente concluída quando da realização do VI CPA em Lima7. Para a concretização desses projetos foi necessária a criação de leis e normas específicas como, por exemplo, a "propriedade horizontal" além de códigos de obras e edificações praticamente inexistentes em vários países latino-americanos. Estes últimos junto às UVs converteram-se nos principais instrumentos racionais de controle e organização do espaço urbano.

As conclusões do VII CPA trazem uma nova guinada às discussões sobre o crescimento e forma das cidades latino-americanas. A comunicação intitulada "Estrutura biológica social das cidades" apresentada pelo arquiteto brasileiro Valentim Pérez de Oliveira Neto colocou em pauta a "criação de organismos de investigação social dos aglomerados humanos e do planejamento orgânico, biológico e social" das cidades (CPA, 1950,

\footnotetext{
${ }^{6}$ Ao respeito das unidades de vizinhança ver: BARCELLOS (2001).

7 A Corporación Nacional de la Vivienda teve importante papel na proposta e construção de unidades de vizinhança em todo o Peru. Para mais informações ver: HUAPAYA (2014b).
} 
p.186), quer dizer, admite-se de forma antecipada o papel central que os "aglomerados humanos" desenvolvem como agentes na própria construção das cidades ${ }^{8}$.

Os seguintes quatro congressos (1952, 1955, 1960 e 1965) foram marcados ainda pela "angustiosa incerteza" e pelo "inquietante desequilíbrio" dos problemas sociais ainda não resolvidos nos anos precedentes (GARCÍA, 1952, p.78). Apesar de que as discussões deram ênfase ao planejamento (nas escalas urbana, regional e nacional) e, de novo, à função social do arquiteto, alguns dos debates e conclusões apontam para a preocupação pela "atividade construtiva" na cidade através do planejamento integral o qual considerava seus aspectos físicos, humanos, econômicos e políticos (GUTIÉRREZ; TARTARINI; STAGNO, 2007, p.76). Ainda falando do planejamento integral este seria, na visão dos congressos, o "único remédio" eficaz para melhorar as condições do ser humano. Isto, na prática, significava ampliar a área de intervenção do arquiteto nas três escalas acima citadas e, por tanto, dar forma ao território nacional; mas também, destacava sua condição principal nas equipes multidisciplinares formadas por técnicos e especialistas que se ocupavam por dar solução aos problemas sociais.

O congresso que teve maior aproximação com as discussões sobre o crescimento e a forma das cidades latino-americanas foi o XII CPA (1968) o qual teve como temática geral a "Renovação urbana". Com esse assunto pretendia-se entender e propor soluções à expansão urbana, à conservação e transformação de áreas centrais e à forma de novas áreas. Algumas das conclusões mostram um câmbio na concepção da cidade a qual não podia ser mais considerada como um "fato abstrato" baseado em "fatos imaginários" (GUTIERREZ; TARTARINI; STAGNO, 2007, p.92). Por essa razão, as formas físicas propostas pelos urbanistas deviam basear-se nos comportamentos culturais e sociais de um grupo social determinado, quer dizer, afirmava-se de que o "marco urbano influenciava a vida social" e "condicionava os comportamentos e valores dos grupos sociais" (CPA, 1968, p.23). Isto levava às seguintes conclusões: a solução dos problemas urbanos não podia ser entendida simplesmente desde um ponto de vista quantitativo, mas, também, era necessário pensar nos aspectos qualitativos. Além disso, as transformações da estrutura física das cidades deviam ser "condicionadas e

\footnotetext{
8 Esses temas terão grande influência a partir da contribuição de John Turner no XII CPA como veremos mais adiante.
}

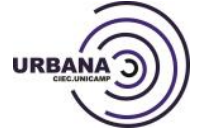

REVISTA ELETRONICA DO CENTRO INTERDISCIPLINAR DE ESTUDOS DA CIDADE - CIEC.UNICAMP v. 7, n. 10, jan /ago (2015). Dossiê História Urbana: a configuração de um campo conceitual 
dirigidas por estudos (sociais, econômicos, ecológicos etc.)" com a finalidade de atingir os "resultados desejados" (CPA, 1968, p.36).

Outro ponto importante é a crítica à percepção do espaço urbano e à obra plástica. Segundo os congressos, ambos tinham naturezas diferentes e consequentemente, baseavam-se, também, em concepções diferentes de espaço. É provável que este tema tenha relação com as discussões sobre os problemas gerados pela degradação e transformação das zonas de interesse histórico e paisagístico. De fato, os congressos faziam um apelo aos governos latino-americanos no sentido de planificar essas áreas baseando-se na Carta de Venezia9 .

Mas, sem dúvida, o maior aporte desse congresso foi resultado da participação do arquiteto John Turner e sua posição sobre as barriadas marginales. Em sua conferência intitulada "El profesional y el desconocimiento de la urbanización espontanea" Turner criticava a visão negativa das urbanizações de formação autônoma (favelas, barriadas etc.) por parte dos arquitetos ao invés deles identificarem as enormes potencialidades das mesmas. Ele ainda observava de que a construção das cidades latino-americanas não era o resultado, necessariamente, da atuação de profissionais titulados, mas que outros agentes como, por exemplo, os mestres de obra, haviam assumido parte dessa atividade (TURNER, 1968, p.76).

Para Turner, as caraterísticas formais das unidades de vizinhança não davam solução adequada ao problema da moradia para a classe menos favorecida na medida em que elas não levavam em consideração os aspectos sociais e culturais dos futuros moradores ${ }^{10}$. Ao contrário da ideia de expansão da cidade através de "propostas racionais", como defendidas pelos congressos, Turner contrapunha a permanência da forma da cidade informal como produto e resultado da própria ação dos moradores, quer dizer, as barriadas não podiam ser desconsideradas dentro da estrutura formal das cidades latino-americanas, pelo contrário, elas faziam parte dela e tinham que ser incorporadas em seu planejamento. Parte destas questões foi desenvolvida de forma

\footnotetext{
9 Essa Carta foi elaborada durante o II Congresso Internacional de Arquitetos e Técnicos de Monumentos Históricos realizado entre o 25 e 31 de maio de 1964. Dois profissionais latino-americanos participaram da sua redação: o arquiteto peruano Victor de Pimentel Gurmendi e o arquiteto mexicano Carlos Flores Marini. 10 Grande parte deles, de forma geral, havia migrado do interior às principais capitais latino-americanas e, portanto, mantinham fortes laços com a vida rural.
} 
mais aprofundada nos encontros promovidos pela Sociedad Interamericana de Planificación (SIAP).

\section{A forma da cidade latino-americana vista através da Sociedad Interamericana de Planificación, 1956-1976}

A criação da Sociedad Interamericana de Planificación (SIAP) em 1956 pode ser entendida como resultado de uma série de discussões sobre o tema que se intensificaram na região a partir do início da década de $1950^{11}$. Sua caraterística principal deve-se ao fato de ser uma Corporación Civil aberta a todos os "profissionais interessados no planejamento democrático e participativo" (CAMACHO, 2007, p. 268), quer dizer, estava formada, além de arquitetos e urbanistas, por engenheiros, sociólogos, administradores, educadores, economistas, advogados etc.

Essa diversidade de visões sobre os diversos problemas enfrentados pelas cidades latino-americanas possibilitou discussões mais ricas, ao estimular e compartilhar experiências de todo o continente. Nesse sentido, os congressos organizados pela SIAP $^{12}$ tiveram papel importante o que pode ser comprovado pelo crescente número de participantes $^{13}$.

A pesar de que esses congressos tiveram sempre a temática voltada especificamente para o planejamento, a partir da década de 1960 foram organizados subtemas de discussão e/ou simpósios que versavam sobre urbanização, desenvolvimento urbano, assentamentos humanos etc. Por exemplo, no VI SIAP, no subtema 2 (Urbanização e desenvolvimento) foram discutidos temas como o crescimento demográfico explosivo, a distribuição regional da população e a produção (TEMARIO, 1965, p.12); no VII SIAP foram discutidos no subtema 4 aspectos culturais na construção das cidades (VII CONGRESO, 1968, p.2, 4-5); no VIII SIAP foi apresentado o simpósio intitulado Polos

\footnotetext{
11 É relevante, também, o aporte dos livros pioneiros sobre o tema de José M. F. Pastor "Urbanismo con Planeamiento (1946), "Curso básico de planeamento urbano y regional" (1950) e "Introducción al Planeamiento Regional" (1956). Alguns dos eventos mais importantes que podem ser citados são o seminário organizado pela Junta de Planificación de Puerto Rico (1951), o Ciclo de Conferencias sobre Planificación y Urbanismo em Lima (1954), o Seminario Internacional sobre la formación de personal para la planificación urbana y rural, em Porto Rico (1956) e a Primera Reunión Técnica Interamericana de Vivienda y Planeamiento organizada pela OEA em Bogotá (1956), evento onde foi criada a SIAP.

12 No período aqui em estudo, foram organizados os seguintes congressos: I SIAP (Bogotá, 1956), II SIAP (Huampaní, 1958), III SIAP (San Juan, 1960), IV SIAP (Santiago, 1962), V SIAP (México, 1964), VI SIAP (Caracas, 1966), VII SIAP (Lima, 1968), VIII SIAP (Salvador, 1970), IX SIAP (Bogotá, 1972), X SIAP (Panamá, 1974) e XI SIAP (Guayaquil, 1976).

13 Por exemplo, no IV SIAP participaram 36 profissionais, no V SIAP 500 e no VI mais de 500.
}

URBANA ()) REVISTA ELETRONICA DO CENTRO INTERDISCIPLINAR DE ESTUDOS DA CIDADE - CIEC.UNICAMP 
de Desarrollo no qual foram discutidos aspectos relacionados aos problemas de urbanização das cidades latino-americanas (NOTICIAS, 1970, p.11); no IX SIAP foi organizado o subtema 9 (Urbanização e câmbio social) o qual tinha por objetivo discutir os câmbios urbanos e sociais nas cidades, os conceitos de marginalidade e integração urbana além da situação dos assentamentos urbanos "no controlados" (NOTICIAS, 1972, p.30) e; no X SIAP, no subtema $V$ (Planejamento da estrutura urbana) o interesse focou-se no papel desempenhado pelos grupos sociais no processo de construção de planos urbanos, na influência das regiões metropolitanas, na descentralização versus concentração, no planejamento de cidades intermedias e medias etc. (NOTICIAS, 1974, p.19).
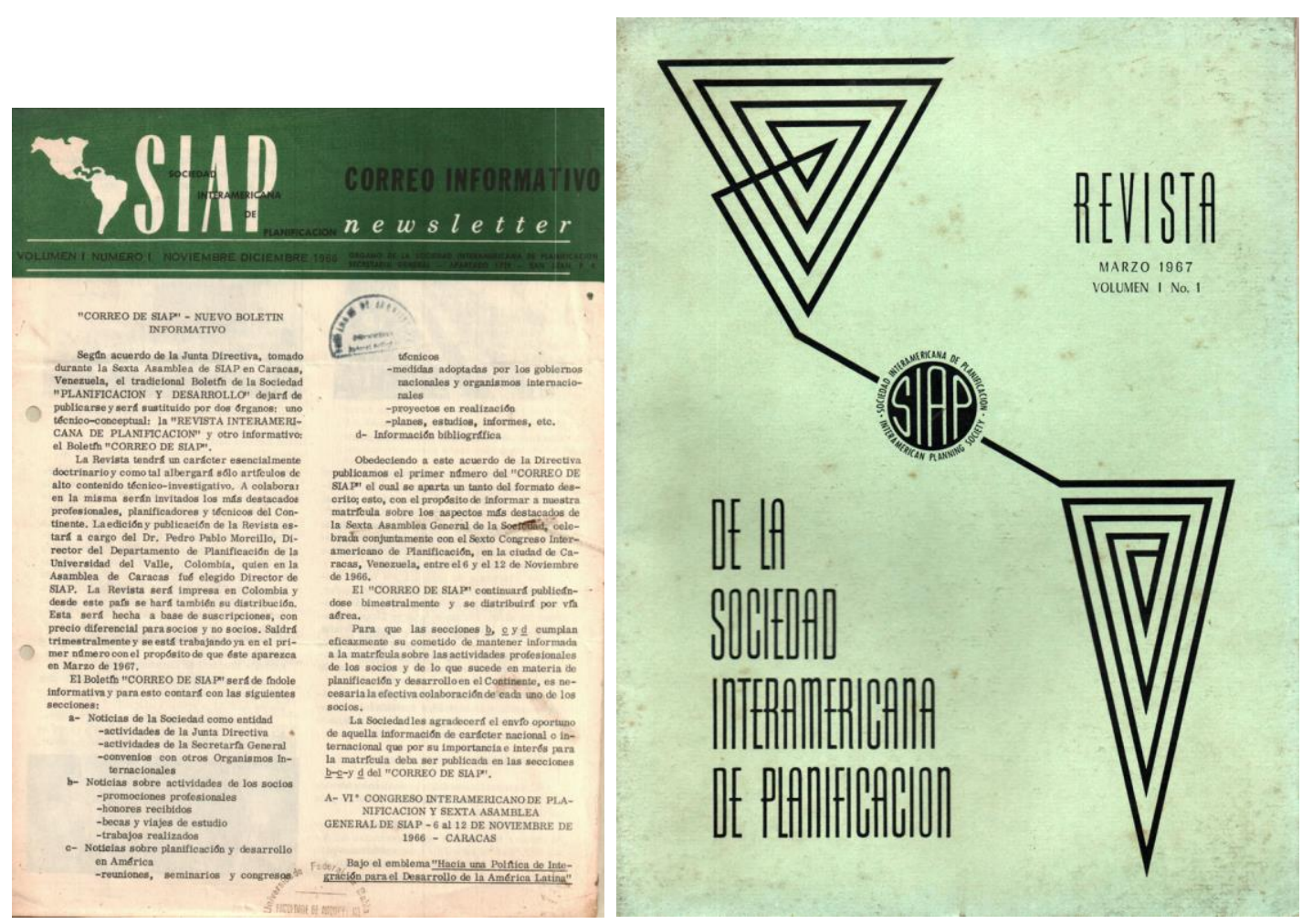

Figuras 4 e 5 - Correo Informativo de la SIAP (n.1, nov./dez. 1966) e Revista de la Sociedad Interamericana de Planificación (n.1, mar. 1967).

Este panorama é diferente se analisamos seus principais veículos de difusão impressos, entre eles, o Boletín Planificación y Desarrollo, o Correo de la Sociedad Interamericana de Planificación e em especial a Revista de la Sociedad Interamericana de

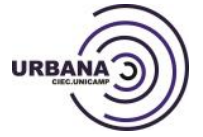

REVISTA ELETRONICA DO CENTRO INTERDISCIPLINAR DE ESTUDOS DA CIDADE - CIEC.UNICAMP 
Planificación ${ }^{14}$. De fato, entre 1967 e 1976 foram publicados na Revista uma série de artigos focados em temas como a história urbana, crescimento e transformações das cidades latino-americanas, a ação dos arquitetos e urbanistas diante desses fenômenos urbanos, os padrões de assentamentos e o problema da moradia popular ${ }^{15}$. Desse conjunto, podemos dar destaque aos artigos "Una nueva función para el arquitecto" (jun. 1967) de Constantinos Apostolos Doxiadis, "El paisaje urbano de Suramérica" (set. 1969) de Jorge E. Hardoy e, "Papel de la elite y patrones de asentamiento en la ciudad Latinoamericana" (mar./jun. 1970) de Peter W. Amato.

O artigo de Doxiadis (1967, p.24) mantém diálogo com as discussões dos CPA sobre a função do arquiteto como "construtor" das cidades num momento de "grandes câmbios" ao afirmar que a esse profissional competiam os "aspectos físicos importantes das agrupações humanas". A partir dessa afirmação ele se questionava sobre qual era a forma dos assentamentos humanos (cidade) que estavam sendo "construídos" e alertava de que os fatos mostravam exemplos "inaceitáveis". Para Doxiadis, a cidade devia ser o resultado do "equilíbrio entre a natureza, o homem e a sociedade e, entre as funções que deveriam ser fornecidas". Assim, a sua forma podia ser entendida através da relação de cinco elementos: natureza, homem, sociedade, recintos e redes que possibilitavam o seu funcionamento. A função do arquiteto, segundo ele, era resultado da reação e não da ação baseada em conhecimentos mais amplos sobre políticas, programas, métodos e sistemas adequados (DOXIADIS, 1967, p.25); no entanto, algumas experiências, como a construção de unidades de vizinhança haviam mostrado, desde seu ponto de vista, contribuições positivas diante desse panorama já que sugeriam preocupação pela construção de "agrupações integradas por células na escala humana" (DOXIADIS, 1967, p.27). Os desafios a serem enfrentados, segundo Doxiadis (1967, p.27), podiam ser superados se fossem levadas as seguintes considerações: 1 . A cidade podia ser subdividida e examinada de acordo a determinadas

14 Até 1966 o Boletín Planificación y Desarrollo publicado bimestralmente foi substituído por duas publicações: o Correo de la SIAP concebido como um meio "informativo" das atividades da SIAP e a Revista Interamericana de Planificación publicada trimestralmente a qual tinha um viés "técnico-conceitual". Ver: CORREO, 1966, p.1.

15 Além dos artigos analisados a seguir, podemos mencionar "La conducta humana y el diseño urbano" (set. 1968) de David Stea, "Nueva estrategia de la vivienda urbana" (set. 1968) de John Turner, "La tarea política y teórica del planificador en América Latina" de Osvaldo Sunkel (dez. 1968), "El desarrollo comunal y planificación urbana en América Latina" de Francis Violich (dez. 1968), "Patrones de vivienda en el desarrollo urbano" de Peter W. Amato (dez. 1968) e "La regionalización de las políticas de desarrollo en América Latina" de Eduardo Neira Alva (dez. 1969). 
disciplinas como: economia, sociologia, tecnologia, arquitetura, estética etc. e; 2 . O estudo das cidades podia ser realizado a partir de "unidades geográficas" (moradia, bairro, cidade, metrópole e região).

O artigo de Jorge E. Hardoy é interessante na medida em que centra sua discussão nos problemas físicos e ambientais causados pelo crescimento desordenado das cidades latino-americanas e na influência que a própria sociedade tem nas "formas urbanas do futuro" (HARDOY, 1969, 29). Seu texto baseia-se em cinco pressupostos, dois deles se relacionam diretamente ao tema aqui em questão: segundo Hardoy (1969, p.28) "nenhuma cidade da América do Sul estava técnica, financeira, institucional e administrativamente preparada para absorver a nova população urbana" e que a pesar dessa situação "a urbanização constitui um processo e reflexo positivo da rebelião espontânea y silenciosa daqueles que não encontram outra opção de trabalho, educação e sobrevivência nas cidades", ou seja, dava ênfase ao papel da própria população em seu processo de formação.

Nessa perspectiva, Hardoy (1969, p.29) considerava que era mais viável, "em países com alto potencial urbanístico" e com processos de urbanização instável, considerar a proposta de novas cidades ou a ampliação das existentes ao contrário de "remodelações" com a finalidade de evitar "conflitos" e grandes despesas econômicas. O grande aporte de Hardoy refere-se ao estudo da evolução da forma das cidades sulamericanas classificadas em quatro modelos: colonial clássico, republicano, da primeira fase industrial e industrial.

De forma geral, ele considerava que a cidade sul-americana era resultado da sua origem colonial a qual evocava a existência de uma malha rígida e ortogonal independentemente do terreno e das características do lugar. Estas características, no entanto, eram diferentes no caso brasileiro onde foi utilizado um modelo particular (HARDOY, 1969, p.30).

Feitas essas ressalvas, o modelo I estava formado por quatro setores ${ }^{16}$. O primeiro era o "centro" de malha regular onde se encontravam a plaza mayor, as melhores moradias e o principal comércio da cidade. No segundo setor, a "zona de transição", encontravamse as moradias de empregados, artesões e famílias "brancas ou mestiças" de ingressos

\footnotetext{
16 Evidentemente, as transformações e causas delas identificadas por Hardoy em cada um dos modelos e setores correspondentes são mais amplas, mas, neste artigo centramo-nos somente naqueles que se relacionam diretamente ao tema proposto.
} 
"médios baixos e baixos". No terceiro setor encontravam-se os subúrbios onde as edificações se encontravam dispersas. O quarto setor era a zona de cultivo e de criação de animais (HARDOY, 1969, p.31).

O modelo II permaneceu até o início do século XIX. Este período foi marcado pela independência dos países da região e pelo desenvolvimento do comércio exterior através da influência inglesa, norte-americana e francesa. Os câmbios da forma urbana das cidades, afirma Hardoy, foram lentos. O primeiro setor apresentou uma expansão mínima em decorrência do crescimento da população urbana. As transformações nos outros setores foram ainda menores (HARDOY, 1969, p.32).

No modelo III o impacto da imigração e a primeira etapa da industrialização provocou entre 1870 e 1920 profundas transformações nas principais capitais. No centro, no primeiro setor, os usos do solo se diversificaram perdendo-se a unidade arquitetônica; nele, segundo Hardoy, construiu-se sem levar em consideração o equilíbrio formal do conjunto. O segundo setor dedicado em especial à moradia foi "absorvido" pelo primeiro setor em constante expansão; nele a expansão urbana foi baseada a partir da reprodução do "traçado colonial". No terceiro setor, as indústrias localizaram-se perto dos centros tradicionais ocasionando a "obsolescência de bairros inteiros". O quarto setor estava formado por uma mistura de áreas de cultivo e "rancheríos" improvisados nos quais se instalaram trabalhadores de indústrias suburbanas. Aparece neste modelo um quinto setor com as mesmas caraterísticas e funções do antigo quarto setor (HARDOY, 1969, p.33-34).

Para Hardoy (1969, p.34-38), o modelo IV, da cidade contemporânea, era o resultado do descompasso entre o processo de urbanização e a adequada industrialização. A isto, ele acrescentava ainda os efeitos dramáticos da explosão demográfica no continente latino-americano iniciados a partir da década de 1940. No setor I, a Plaza de Armas deixou de cumprir seu papel como polo gerador da atividade comercial a qual se expandiu provocando "uma intensa concentração de escritórios nos centros tradicionais". O setor II foi praticamente incorporado ao setor I, ele apresenta densidades diversas e encontramos uma predominância de habitação, porém, com serviços comerciais e institucionais; além disso, a "qualidade e variedade das instituições e os contrastes entre o traçado de algumas vias e a modesta estética da rua estão intimamente ligados ao grupo social que reside em cada área", ou seja, iniciase o atual processo de setorização da cidade desde o ponto de vista econômico e social.

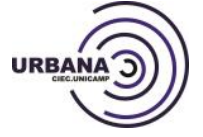

REVISTA ELETRONICA DO CENTRO INTERDISCIPLINAR DE ESTUDOS DA CIDADE - CIEC.UNICAMP 75 v. 7, n. 10, jan /ago (2015). Dossiê História Urbana: a configuração de um campo conceitual 
O setor III estava conformado por três zonas: na primeira instalou-se grande parte da atividade industrial; a segunda, basicamente, foi constituída pela residência das classes alta e média e; na terceira desenvolveram-se as favelas, villas miserias, e barriadas a partir dos movimentos migratórias do campo às principais capitais. A presença dessa nova população na cidade, segundo Hardoy, "constituíram um novo elemento da estrutura urbana". O setor IV era o limite da área metropolitana "em processo de industrialização, indefinido e com usos misturados que não necessariamente se complementavam". O setor V, constituído por "aglomerações menores", acabou incorporando-se à área metropolitana; esses aglomerados, na sua maioria, eram "cidades dormitório" ou, em outros casos, "indústrias menores". Aparece mais um setor, o VI, formado pela área de cultivo e de criação de animais a qual se afastou, aproximadamente, "dez, quinze ou vinte quilômetros" do centro da cidade.

Diante desse cenário, Hardoy via com incerteza qual seria o caminho da "paisagem urbana" dos países latino-americanos a qual, segundo ele, havia mudado completamente em trinta anos. No entanto, para ele quatro fatores seriam decisivos para o futuro do "meio ambiente urbano": a tecnologia utilizada, os níveis de ingresso da população, a política de controle de inversões do setor público e a atitude do setor privado.

No artigo de Amato encontramos outra forma de entender os processos de urbanização e a forma da cidade latino-americana através da ação, influência e atividades da elite urbana ${ }^{17}$. Mantendo semelhanças e aproximações como o estudo de Hardoy, Amato considerava de que a forma dos assentamentos na América Latina havia mudado consideravelmente ao longo do tempo e que nesse processo as formas de ocupação do uso do solo por parte da elite haviam sido determinantes.

Este fenômeno, segundo Amato (1970, p.23), responde diretamente à necessidade de localização das residências das classes economicamente mais favorecidas e é explicado através de três aspectos: o primeiro tem a ver com a acessibilidade ao centro das cidades, quer dizer, as residências poderiam estar localizadas em zonas mais afastadas do centro sempre e quando o acesso rápido às atividades de trabalho, lazer etc., fosse garantido; o segundo aspecto vincula-se com o local eleito para essas áreas

\footnotetext{
17 Segundo Amato (1970, p.22) entender esses efeitos na cidade se constituía no principal desafio do planejador, que tinha a finalidade de "desenvolver políticas de uso do terreno urbano mais coerentes e claras".
} 
residenciais, para Amato, a elite fez a escolha dessas zonas dependendo das suas caraterísticas particulares assim, por exemplo, áreas inundáveis ou de risco foram descartadas e; o terceiro aspecto tem a ver com as "características sociais e físicas da vizinhança imediata". Diante desse panorama, para ele, os "movimentos" da elite na cidade não respondiam a processos desorganizados, pelo contrário, eles eram resultado de "um claro propósito" em busca de terras mais vantajosas em termos ambientais e de lazer. Em outras palavras, segundo Amato, os membros da elite disfrutaram do "más amplio surtido al escoger dónde y en que forma" desejavam morar. Todas essas hipóteses foram sustentadas y comprovadas através do estudo de quatro capitais: Bogotá, Quito, Lima e Santiago do Chile.

Ainda, segundo Amato (1970, p.29), o planejador devia ser o principal artífice da forma da cidade. Seu crescimento e desenvolvimento dependiam, em especial, da relação entre os serviços urbanos e o custo em términos de tempo e energia para o translado de pessoas, bens e serviços. Portanto, isto implicava e envolvia questões políticas no uso do solo que, no caso das cidades latino-americanas, refletiam por um lado a ineficiente gestão governamental ao incentivar o "crecimiento desequilibrado causado por una zonificación exclusiva y restringida" e, pelo outro, o intenso controle e influência sobre a forma do espaço da cidade por parte da elite.

\section{América Latina vista pelos latino-americanos. Formulações teóricas para a compreensão da forma da cidade latino-americana}

Mas, o campo de ação da SIAP no sentido de possibilitar uma maior difusão, discussão e circulação de ideias sobre o planejamento e o estudo dos problemas das cidades na América Latina foi ampliado através da publicação de livros especializados editados pela própria sociedade ${ }^{18}$. Como indica Camacho (2007, p.274), entre as décadas de 1970 e 1980 foram publicados 31 títulos que mostram, por um lado, a partir das temáticas abordadas, as preocupações, interesses e desafios a serem enfrentados pelas principais cidades da região. Mas, pelo outro, eles também evidenciam o empenho pela construção

\footnotetext{
18 A Editorial Ediciones SIAP foi criada em 1970 através de um financiamento da Fundação Ford (CAMACHO, 2007, p. 274). O comitê editorial estava formado por Jorge E. Hardoy (presidente), Cuauhtémoc Cárdenas, Ralph Gakenheimer, Alajandro Rofman e José A. Silva Michelena. Já a Direção Executiva foi assumida por Martha S. de Kaplan.
} 
de uma base teórica apropriada à realidade latino-americana elaborada, em especial, pelos próprios profissionais latino-americanos ${ }^{19}$.

Apesar de que o foco principal da editora foi centrado no estudo do planejamento a partir de diversos enfoques (econômico, urbano, político, social etc.) ${ }^{20}$, três publicações tiveram como mote de discussão questões relacionadas aos processos de urbanização e à forma das cidades latino-americanas: "La investigación urbana latinoamericana: tendencias y planteos" (1971) de Richard M. Morse, "La estructura interna de la ciudad. El caso latinoamericano" (1971) de Oscar Yujnovsky e, "Historia urbana. Una metodología aplicada" (1978) de Armando de Ramón.
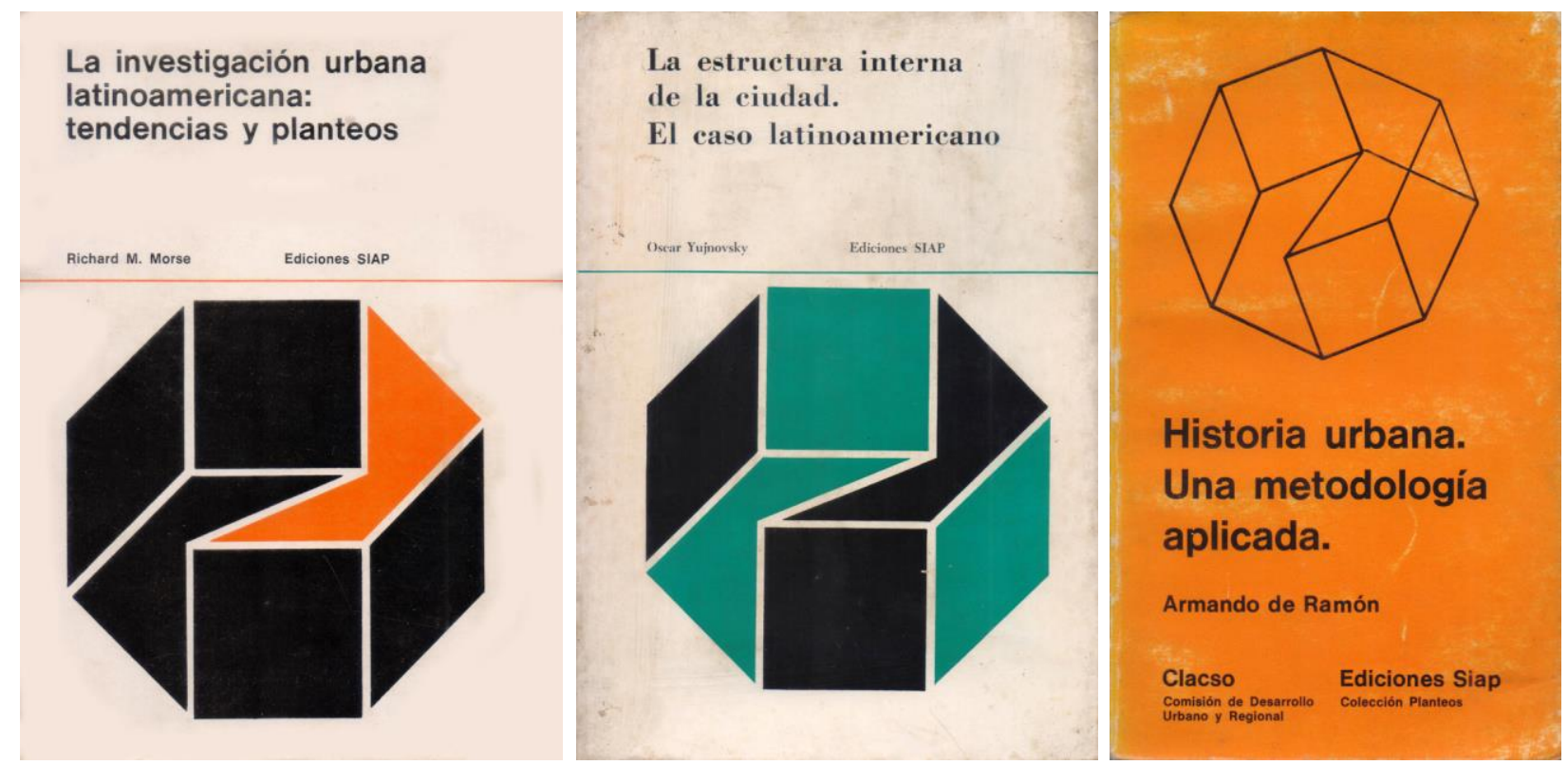

Figuras 6, 7 e 8 - Capas dos livros de Richard M. Morse (1971), Oscar Yujnovsky (1971) e Armando de Ramón (1978).

\begin{abstract}
19 De fato, a da solução dos problemas latino-americanos pelos próprios latino-americanos era uma ideia que foi reforçada e defendida, em especial, a partir da década de 1960, ao respeito ver: HUAPAYA (2015). ${ }^{20}$ Entres eles podemos mencionar: "Países y ciudades. Comparación de estrategias para el crecimiento urbano" (1972) de Lloyd Rodwin, "El desarrollo regional en América Latina. Experiencias y perspectivas" (1972) de Walter B. Stöhr, "Segregación residencial y desmovilización política. El caso de Lima" (1973) de A. Rodríguez, "Movimientos sociales urbanos" (1975) de Jordi Borja, "Las ciudades de América Latina y sus áreas de influencia a través de la historia" (1975) de Jorge E. Hardoy e Richard P. Schaedel, "Una política regional de industrialización. El Nordeste brasileño" (1976) de Raimundo Moreira e, "Ciudad Guayana y la estrategia del desarrollo polarizado" (1977) de Maritza Izaguirre P.
\end{abstract}


CIEC

A primeira publicação da editorial SIAP foi o livro La investigación urbana latinoamericana: tendencias y planteos de Richard Morse ${ }^{21}$ com o qual se tentou realizar uma revisão, balance e análise sistemático dos estudos sobre a urbanização na América Latina realizados entre 1960 e $1970^{22}$.

É interessante assinalar a valorização que Morse dá às cidades pré-colombianas no próprio processo de formação e continuidade de algumas cidades latino-americanas como os casos de Tenochtitlán e Cuzco. Para ele, o "estudio de la historia urbana desde los tiempos precolombinos hasta el presente es [seria] ciertamente posible para gran parte de América Latina" (MORSE, 1971, p.10), porém, a ruptura do século XVI provocou, entre outras consequências, o deslocamento massivo dos povos indígenas, a reorientação das economias e a imposição de tecnologias e formas urbanas europeias. O modelo de cidade trazido pelos espanhóis durante a conquista teve grande influência daquele utilizado nas "ciudades de meseta" espanholas que foram, por sua vez, resultado de "factores políticos y militares" após a reconquista peninsular. Já no caso das colônias portuguesas o modelo reproduzido foi o da cidade medieval que respondia mais a questões econômicas do que a fins político-militares e que possuía, geralmente, segundo ele, traçado espontâneo o natural.

Assim, para Morse (1971, p.76), a análise funcional, mas também a morfológica, das cidades hispano-americanas tinha que levar em consideração a "herança" espanhola. Como veremos mais adiante, a discussão sobre o modelo utilizado gerou diversas hipóteses dentre as quais Morse destaca a proposta innovativa de Kuble, que defendia que a forma dos povos indígenas pôde ter afetado e condicionado os traçados espanhóis; a replicativa de Stanislawski, que acreditava que diante da necessidade de um "plano urbano" os espanhóis tiveram que beber de fontes antigas como, por exemplo, os preceitos vitruvianos; a formalista de Foster, que sustentava a ideia do modelo como resultado do desejo "burocrático de amplitude de espacio y simetria" que tinham acompanhado o desenvolvimento político nacional; o imperialista de Palm, que defendia o "geometrismo" como a vontade imperial de dominar as terras conquistadas de forma racional; a tradicionalista de Guarda, que apoiava a tese da influência do

\footnotetext{
${ }^{21}$ O livro foi o resultado de três artigos publicados por ele na revista norte-americana Latin American Research Review em 1965 e 1971.

22 Além disso, essa publicação merece destaque por realizar um levantamento da principal bibliografia sobre o tema.
}

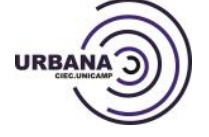

REVISTA ELETRONICA DO CENTRO INTERDISCIPLINAR DE ESTUDOS DA CIDADE - CIEC.UNICAMP 
planejamento urbano usado nas Índias e; a pragmática de Hardoy, que afirmava que esse modelo não é mais do que o resultado de "décadas de prueba de error" na busca de uma cidade ideal das Índias que só foi possível em 1573 quando a "experiencia acumulativa de los colonos fue codificada haciendo concesiones a la elegancia clásica". Em La estructura interna de la ciudad Yujnovsky adverte que as mudanças da sociedade e seus efeitos na urbanização haviam chamado a atenção dos pesquisadores em todo o mundo. No caso específico dos países da América Latina, o interesse se havia voltado para a "busca por compreender los problemas del subdesarrollo y sus causas" (YUJNOVSKY, 1971, p.10). A forma da cidade, segundo ele (1971, p.17 e 19), não podia ser entendida somente através de aspectos físicos, pelo contrário, ela era resultado de um "sistema urbano" dinâmico composto por diversas atividades realizadas no espaço urbano $^{23}$. Assim, os "tipos y formas de interrelación entre las diferentes atividades" constituíam-se em aspectos que possibilitavam o entendimento dos processos de urbanização, da expansão das zonas ocupadas pela cidade, das formas de relações econômico-espaciais entre os distintos componentes da economia urbana, do surgimento e funcionamento dos "bairros" e de áreas sociais, além do benefício das distintas classes sociais aos benefícios da vida urbana (YUJNOVSKY, 1971, p.11).

Para Yujnovsky, o desenvolvimento da teoria urbana foi fortalecido pelos "hallazgos teóricos", em grande parte, da sociologia, mas, também, da geografia urbana, da ecologia, da história, da antropologia, da psicologia social, entre outros. Ou seja, ele chamava a atenção para o enfoque multidisciplinar da cidade e para a necessidade de se elaborarem mais investigações para entender os processos que "hoy ocurren en las ciudades latinoamericanas" identificando problemas e explicando causas (YUJNOVSKY, 1971, p.12).

De forma similar a Hardoy, Yujnovsky (1971, p.47) tentou entender e explicar o processo de formação da estrutura e forma das cidades latino-americanas usando um enfoque histórico. Ele identificou sete etapas de urbanização: civilização précolombiana, exploração e conquista (1492-1530), cidade colonial (1530 até meados do século XVIII), crescimento colonial (meados do século XVIII até 1810), período

\footnotetext{
${ }^{23}$ Entre elas, as atividades industriais, os serviços e a moradia. Mantendo diálogo com Amato, ele dava ênfase às necessidades de mobilidade e contato das pessoas e mercadorias (YUJNOVSKY, 1971, p.10). Ele (1971, p.19-20) também especificava de que o "sistema espacial urbano" estava conformado por quatros subsistemas: o social, o econômico, o cultural e o político.
} 
republicano (1810 até o início da segunda metade do século XIX), crescimento sobre a base do modelo tradicional (segunda metade do século XIX até, aproximadamente, 1930) e, período de 1930 até a atualidade (YUJNOVSKY, 1971, p.48).

É importante destacar alguns aspectos dessa classificação. Por um lado, a incorporação e influência das cidades pré-colombianas no próprio processo de formação e localização de centros urbanos ${ }^{24}$, mas também, pelo outro, o impacto reduzido destas nas estruturas internas urbanas das cidades contemporâneas. Algo similar acontece com a segunda etapa na qual, segundo Yujnovsky (1971, p.48), não foram criados estabelecimentos permanentes ${ }^{25}$. Segundo ele, é a partir de 1530, desde o ponto de vista da estrutura urbana, que é possível falar em "estructura física de la ciudad colonial hispanoamericana". Posteriormente, essa situação foi favorecida pela Lei das Índias.

A forma urbana das cidades coloniais foi resultado, na visão de Yujnovsky (1971, p.60), "de aquello que imperaba en la Metrópoli". Mas, adverte que esse modelo não era aplicado de forma direta senão que incorporava "los resultados de la experiencia y del contacto con las nuevas condiciones del Nuevo Mundo". De forma geral, o modelo aplicado à América hispana era caracterizado pela forma regular e era derivado das cidades agro militares da meseta central espanhola construídas no processo de reconquista de terras após a dominação do Islam. No obstante essa generalização, ele identificou quatro variações físicas: adaptações a planos pré-colombianos, fortes, estrutura em damero ${ }^{26}$ e, agrupamentos espontâneos de edificação irregular (especialmente, no caso brasileiro). O elemento central é também para Yujnovsky a Plaza Mayor. Apesar de que o mesmo é inexistente na tradição portuguesa chama a atenção para seu equivalente o Rossio ou o Largo. Já na etapa republicana a forma e estrutura das cidades mantém ainda as caraterísticas coloniais. O principal câmbio foi de ordem qualitativa no regime social; por exemplo, a situação da falta e da localização da moradia continuou sendo um problema sem resolver e os regimes de propriedade rural e urbana continuaram sem sofrer alterações.

O período de crescimento sobre a base do modelo tradicional é caraterizado pela acelerada urbanização e modificação das estruturas ecológico-demográficas. Este

\footnotetext{
${ }^{24}$ Como vimos anteriormente, o aporte das cidades pré-colombianas foi também defendido por Morse.

25 Ele afirma que nessa etapa de "penetração e conquista" do continente, os principais câmbios têm a ver como a construção de fortes ou "factorías" precários.

26 Malha regular perpendicular caraterística nas cidades hispano-americanas.
}

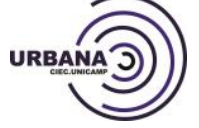

REVISTA ELETRONICA DO CENTRO INTERDISCIPLINAR DE ESTUDOS DA CIDADE - CIEC.UNICAMP v. 7, n. 10, jan /ago (2015). Dossiê História Urbana: a configuração de um campo conceitual 
cenário responde a processos de ordem externo e interno dentre os quais Yujnovsky (1971, p.65) destaca: as exportações de matérias primas latino-americanas, exportação de capitais desde os países "cêntricos", organização nacional, fim das lutas internas e estabilidade política. Segundo esses aspectos ele identifica três tipos de cidades: aquelas que não experimentaram mudanças de desenvolvimento urbano, as que se beneficiaram do desenvolvimento urbano (em especial, as capitais) e, os "novos centros" espontâneos ou planejados que surgiram como forma de conquista de territórios. A forma física dessas cidades ainda foi desenvolvida a partir do damero regular, porém, aparecem ruas e avenidas mais amplas, além de bulevares que em alguns casos cortam a malha regular em diagonal ${ }^{27}$. Os centros experimentaram processos de densificação ao aparecer edifícios em altura com comércio nos térreos ${ }^{28}$. Já no período após 1930 termina o crescimento das cidades baseado no setor externo e é marcado pela crise do capitalismo e a consequências das duas guerras mundiais e a crise de 1929 (YUJNOVSKY, 1971, p.81). A forma da cidade vai ser "controlada" a partir da difusão e aplicação do "código de edificação" no qual foram fixadas normas "sobre zoneamento e critérios de construção" (YUJNOVSKY, 1971, p.84). Além disso, aparecem as "primeiras tentativas de planejamento com critério contemporâneo"29. A partir do tamanho populacional, Yujnovsky (1971, p.88) identifica três tipologias urbanas: as áreas metropolitanas entendidas como "áreas multifuncionais" e onde produziram-se fenômenos de "conurbación" e "constelación" entorno de centros secundários e terciários; as cidades medias não planejadas e; as cidades planejadas (Brasília, Ciudad Guayana etc.).

Algumas das conclusões do estudo de Yujnovsky (1971, p.100) apontam para a ideia de que a cidade latino-americana era produto de "estructuras nascidas de la concretización de funciones", da dependência nacional e interna. Além disso, chamava a atenção para a necessidade de estudos sobre as estruturas internas da cidade com a finalidade de construir tipologias levando em consideração as seguintes variáveis: sistema de decisão ou de distribuição de recursos, tamanho populacional, caraterísticas demográficas, composição da estrutura econômica, nível econômico, estratificação

\footnotetext{
27 Neste ponto, evidentemente, Yujnovsky refere-se às transformações urbanas das principais capitais latino-americanas a partir do modelo haussmaniano.

${ }^{28}$ Este período guarda várias semelhanças com o modelo II proposto por Hardoy.

${ }^{29}$ A "atividade planificadora", segundo Yujnovsky (1971, p.84) foi desenvolvida no marco sócio-político vigente.
} 
social e distribuição de ingressos, pautas culturais, tecnologia, caraterísticas geográficas e naturais e, posição relativa no macro sistema. Quer dizer, como vimos anteriormente, a visão da forma da cidade desde um ponto meramente físico era superada.

Já Armando de Ramón em Historia urbana. Uma metodologia aplicada adverte que as pesquisas sobre a evolução histórica do continente americano se haviam centrado com maior ênfase através da sua história econômica deixando de lado as "estructuras sociales y administrativas que formaban parte del contexto global" (RAMÓN, 1971, p.9). Tomando como objeto de investigação a cidade colonial hispano-americana e mais especificamente o caso de Santiago do Chile e levando em consideração os aspectos anteriormente citados ele realizou um interessante estúdio que tinha por objetivo "restaurar el verdadeiro plano" dessa cidade em 1700. Ou seja, ele demostrava que os estudos da história urbana permitiriam "reconstruir" a malha, superfícies e forma das cidades em períodos determinados.

A forma dessa cidade no século XVII, segundo De Ramón, ou melhor, como ele afirmava, dos "conjuntos poblacionales" ${ }^{10}$, podia ser explicada e entendida a partir dos seguintes elementos: 1. Limites urbanos, somente no século XVIII inicia-se seu processo de expansão mesmo não tendo sido consolidada a área da malha inicial; 2. Extramuros e setor urbano; esses dois setores estavam determinados pela subdivisão da propriedade dentro "de una manzana y edificación de todos o casi todos los prédios contenidos en ella", ou seja, refere-se à ideia de áreas concentradas; 3. Divisão setorial (bairros), no caso chileno o conceito de "bairro" tinha dois sentidos, um quando era usado na área central o qual se relacionava à localização de algum prédio específico e o outro era usado nas áreas de expansão onde o sentido se relacionava à setorização ${ }^{31}$ e; 4. Divisão territorial (paróquias), outra maneira de entender a forma e organização da cidade, segundo De Ramón, era através dos "límites entre las parróquias urbanas" (no caso de Santiago foram as do Sagrario, Santa Ana e São Isidro). Esse olhar sobre a cidade proporciona uma ideia diferente do conceito do "urbano" (como o próprio De Ramón afirma) além de uma leitura distinta das propostas anteriormente citadas aonde,

\footnotetext{
30 Segundo ele, não era possível no século XVII falar de uma "realidade urbana" como a caracterizada na cidade contemporânea. A ideia de "urbano" relacionado com "cidade" naquele momento equivalia "a decir muy poco o más bien nada" (RAMÓN, 1971, p.15).

31 No primeiro dos casos De Ramón dava como exemplo o "bairro" das freiras da ordem Agustina tendo como referência a localização do Convento respectivo.
} 
como vimos, o resultado da forma urbana girava, basicamente, em torno dos próprios processos de crescimento.

Para De Ramón (1971, p.169) o desenvolvimento histórico das cidades hispanoamericanas devia ser estudado levando em consideração dois aspectos: a "análisis de la real o presunta intención, objeto o motivo con que se fundó el establecimiento urbano y de los requisitos que permitieron su consolidación" e a "reflexión sobre el proceso que llevó a la ciudad a transformarse en un fin de sí misma". Dessa forma, ele questionava e relativizava a teoria que defendia a aplicação do "traçado" espanhol como "modelo" para delinear as cidades fundadas na colônia. Pelo contrário, ele afirmava que além dela, era necessário levar em consideração outros estudos que explicavam a origem das mesmas como a de Erwin Walter Palm, que defendia que as plantas das cidades era o resultado da necessidade de encontrar "amplitud de espacio y simetría mediante un programa racionalmente concebido y ejecutado" (RAMÓN, 1971, p.170) ou, aquelas que defendiam que a forma delas era produto das primeiras experiências realizadas no Caribe, no norte e, finalmente, no sul do continente americano (RAMÓN, 1971, p.171). Quer dizer, a forma das cidades era o resultado de "experiências" que tiveram influência de "diversa origem" e não somente de uma aplicação direta de plantas trazidas da Espanha.

\section{Considerações finais}

A análise dos debates e das temáticas dos CPA e dos encontros da SIAP nos permite vislumbrar alguns aspectos relevantes que nos ajudam a entender os aportes de ambos na reflexão sobre a forma urbana latino-americana. 1. O período compreendido entre 1920 (I CPA) e 1976 (XI SIAP) pode ser subdividido em dois momentos tendo como ponto de inflexão a Segunda Guerra Mundial; 2. No primeiro deles (pré-guerra) aconteceram somente os CPA e, basicamente, as discussões giraram em torno da construção da história da arquitetura latino-americana. Assim, temas relacionados à "forma urbana" das cidades na América Latina são escassos ou pontuais; 3. Esse panorama muda consideravelmente logo após o período pós-guerra onde os problemas causados pelas intensas migrações às principais capitais iniciou uma série de reflexões sobre qual seria o futuro das cidades na região; 4. Esse segundo momento foi o mais rico nas discussões sobre a "forma urbana" das cidades na América Latina tanto nos CPA quanto nos encontros da SIAP, porém, é possível afirmar de que apesar de que

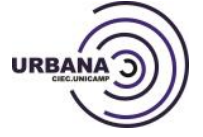

REVISTA ELETRONICA DO CENTRO INTERDISCIPLINAR DE ESTUDOS DA CIDADE - CIEC.UNICAMP v. 7, n. 10, jan /ago (2015). Dossiê História Urbana: a configuração de um campo conceitual 
nestes últimos o foco principal estava direcionado ao planejamento (urbano, regional e nacional) foram eles os que deram maior aporte ao tema; 5. Existe, não entanto, a partir da década de 1960, sintonia entre ambos os eventos tematicamente falando, quer dizer, nessa década temas como o planejamento, os problemas das cidades latinoamericanas, a função social do arquiteto etc., tornaram-se centrais; 6. É justamente nesse período que surgem as discussões sobre quem deveria ser o profissional encarregado de dar formas às cidades, se num primeiro instante os CPA defendem que deveria ser o arquiteto, posteriormente, acreditava-se que deveria ser o planejador ${ }^{32}$; 7. Ainda falando na década de 1960 é possível perceber que as diversas pesquisas e estudos realizados têm como objetivo principal elaborar uma base teórica que explique o fenômeno da cidade latino-americana, assim, teorias elaboradas em contextos diferentes (como nos EUA e na Europa) vão ser simplesmente desconsideradas; 8. A pesar disso, chama a atenção um fato. Justamente nesses anos identificasse uma mudança na compreensão da cidade, assim, esta passa a ser entendida não só como produto de suas caraterísticas físicas, mas também a partir de seus aspectos inerentes (sociais, econômicos, históricos, políticos etc.) 33; 9. Essa "nova" visão foi decisiva para relativizar a ideia do controle racional da forma da cidade, pelo contrário, áreas antes desconsideradas ou consideradas como "irracionais" (favelas, barriadas, por exemplo), passaram a formar parte da realidade urbana latino-americana; 10 . Finalmente, como mencionado antecipadamente, foi relevante o papel da SIAP na difusão de todo esse conjunto de reflexões através da sua revista especializada e dos livros publicados.

\section{Referências}

\footnotetext{
32 Apesar de que essa função não estaria restringida a um profissional específico, acreditava-se, no entanto, que o arquiteto por seus conhecimentos, era o profissional apto. Porém, ele devia cursar uma especialização respectiva.

33 E interessante notar que justamente nesse período foi publicado o livro L'architettura della città (1966) de Aldo Rossi, que defende a ideia do fato urbano como forma de compreender mais eficientemente a cidade. Nesse sentido, encontram-se vários pontos em comum com as propostas e reflexões das teorias latino-americanas embora não fossem identificadas referências diretas a Rossi.
} 
VII CONGRESO Interamericano de Planificación, efectuado en Lima, Perú. Correo Informativo de la Sociedad Interamericana de Planificación, v.3, n.5-6, set./dez. 1968, p.2-6.

AMATO, Peter W. Papel de la elite y patrones de asentamiento en la ciudad latinoamericana. Revista de la Sociedad Interamericana de Planificación, v. IV, n.1314, mar./jun. 1970, p.22-34.

ATIQUE, Fernando. O debate sobre Habitação nos Congressos Pan-Americanos de Arquitetos: 1920-1940. In: ENCONTRO NACIONAL DA ANPUR, 11, 2005, Salvador. Anais do XI Encontro Nacional da ANPUR. Salvador: ANPUR, 2005.

. Congresso Pan-Americano de Arquitetos: Ethos continental e herança europeia na formulação do campo do planejamento (1920-1960). URBANA - Revista Eletrônica do Centro Interdisciplinar de Estudos sobre a Cidade, v.6, n.8, 2014, p.14-32.

BARCELLOS, Vicente Quintela. Unidade de vizinhança: notas sobre sua origem, desenvolvimento e introdução no Brasil. Cadernos Eletrônicos da Pós- Universidade de Brasília, Faculdade de Arquitetura e Urbanismo, 2001, p. 1-28.

CAMACHO, Luis Eduardo. Sociedad Interamericana de Planificación, SIAP 50 años. Vida institucional y programática. Revista Bitácora Urbano Territorial, ano 1, v. 1, n. 11, jan./dez. 2007, p. 268-284.

CONCLUSIONES DEFINITIVAS del III Congreso Panamericano de Arquitectos. Revista de Arquitectura, ano XIII, n.80, ago. 1927, p.313-316.

CORREO DE SIAP, nuevo Boletín Informativo. Correo Informativo de la Sociedad Interamericana de Planificación, v. 1, n.1, nov./dez. 1966, p.1.

CPA - CONGRESOS PANAMERICANOS DE ARQUITECTOS. Actas y trabajos del Primer Congreso Panamericano de Arquitectos. Montevideo: Imprenta y Casa Editorial Renacimiento, 1921.

- V Congreso Panamericano de Arquitectos. Publicación Oficial de Actas y trabajos. Montevideo: Talleres Gráficos Urta y Curbelo, 1940.

Memoria del VII Congreso Panamericano de Arquitectos. Havana: Ed. Ucar García S. A., 1950.

María, 1953.

Actas del VI Congreso Panamericano de Arquitectos. Lima: Imprenta Santa XII Congreso Panamericano de Arquitectos. Bogotá: Editorial Pax, 1968.

DOXIADIS, C. A. Una nueva función para el arquitecto. Revista de la Sociedad Interamericana de Planificación, v.1, n.2, jun. 1967, p.24-29.

GARCÍA TRAVESI, Gustavo. La importancia del VIII Congreso Panamericano de Arquitectos. Universidades de Latinoamérica, ano III, n.16, out. 1952, p.78.

URBANA (3) REVISTA ELETRONICA DO CENTRO INTERDISCIPLINAR DE ESTUDOS DA CIDADE - CIEC.UNICAMP v. 7, n. 10, jan /ago (2015). Dossiê História Urbana: a configuração de um campo conceitual 
GOMES, M. A. A. F; HUAPAYA ESPINOZA, José Carlos. Olhares cruzados: visões do urbanismo moderno na América do Sul. In: GOMES, M. A. A. F. (Org.). Urbanismo na América do Sul: circulação de ideias e constituição do campo, 1920/1960. Salvador: EDUFBA, 2009, p. 13-39.

GUTIÉRREZ, Ramón; TARTARINI, Jorge; STAGNO, Rubens. Congresos Panamericanos de Arquitectos 1920-2000: aportes para su historia. Buenos Aires: CEDODAL, 2007.

HARDOY, Jorge E. El paisaje urbano de Suramérica. Revista de la Sociedad Interamericana de Planificación, v. III, n.11, set. 1969, p.27-41.

HARTH-TERRÉ, Emilio; GOYTISOLO, Alberto; MORALES MACHIAVELLO, Carlos. Proyecto de reforma y ampliación de la enseñanza de la arquitectura en la Escuela de Ingenieros. Lima: Imp. Segrestán Trujillo, 1930.

HUAPAYA ESPINOZA, José Carlos. Fernando Belaunde Terry y el ideario moderno. Arquitectura y urbanismo en el Perú entre 1936 y 1968 / Fernando Belaunde Terry e o ideario moderno. Arquitetura e urbanismo no Peru entre 1936 e 1968. Lima: EDUNI/EDIFAUA, 2014a.

Hacia una nueva concepción de la vivienda en el Perú. Los aportes de la Corporación Nacional de la Vivienda, 1945-1956. Wasi. Revista de estudios sobre vivienda, v. 1, n.2, 2014b, p. 65-76.

Eduardo Neira Alva. Aportes profesionales para el debate sobre el desarrollo territorial y la ecología urbana en América Latina, 1961-1998. In: ENCONTRO NACIONAL DA ANPUR, 16, 2015, Belo Horizonte. Anais do XVI Encontro Nacional da ANPUR. Belo Horizonte: ANPUR, 2015.

LIERNUR, Jorge Francisco. Vanguardistas versus expertos. Reconstrucción europea, expansión norteamericana y emergencia del "Tercer Mundo": para una relectura del debate arquitectónico en la segunda posguerra (una mirada desde América Latina). Block, n. 6, mar. 2004, p. 18-39.

MORSE, Richard M. La investigación urbana latinoamericana: tendencias y planteos. Buenos Aires: Ediciones SIAP, 1971.

NOTICIAS de la Secretaria General. Correo Informativo de la Sociedad Interamericana de Planificación, v. 4, n.12, jan./fev./mar. 1970, p.11.

. Correo Informativo de la Sociedad Interamericana de Planificación, v. 6, n.1, jan./fev. 1972, p.30.

. Correo Informativo de la Sociedad Interamericana de Planificación, v. 8, n.1, jan./fev. 1974, p.19.

RAMÓN, Armando de. Historia urbana. Una metodología aplicada. Buenos Aires: Ediciones SIAP/CLACSO, 1971. 
TEMARIO del VIO Congreso Interamericano de Planificación. Planificación y desarrollo. Boletín de la Sociedad Interamericana de Planificación, v. 3, n.38, jul./ago. 1965, p.16.

TURNER, John F. C. El profesional y el desconocimiento de la urbanización espontánea. In: CPA. XII Congreso Panamericano de Arquitectos. Bogotá: Editorial Pax, 1968, p.7579.

YUJNOVSKY, Oscar. La estructura interna de la ciudad. El caso latinoamericano. Buenos Aires: Ediciones SIAP, 1978. 